\title{
Frequency of autoimmune thyroiditis in children with Celiac disease and effect of gluten free diet
}

\author{
Javaria Rasheed ${ }^{1}$, Rushan Hassan², \\ Muhammad Khalid ${ }^{3}$, Fauzia Zafar
}

\begin{abstract}
Objective: To determine the frequency of autoimmune thyroiditis in children with Celiac disease and the effect of gluten free diet on autoimmune thyroiditis.

Methods: We enrolled 100 patients, age 1-12 years of either gender diagnosed as Celiac disease (CD) in this prospective observational study in the Department of Pediatric Medicine, from $1^{\text {st }}$ January 2018 to $30^{\text {th }}$ June 2019. Diagnosis of autoimmune thyroiditis was made if anti-thyroperoxidase $>35 \mathrm{iu} / \mathrm{ml}$ or antithyroglobulin $>20 \mathrm{iu} / \mathrm{ml}$ at diagnosis of $\mathrm{CD}$ and then at one year on gluten free diet (GFD) in all cases. Children with repeat anti-tTG levels > 10 times upper limit normal at 6-months after enrollment were labelled as non-compliant to GFD. Descriptive statistics were used to analyze the data.

Results: Mean age of the participants was $5.94 \pm 3.16$ years and $53 \%$ were females. Fourteen cases of autoimmune thyroiditis were detected at enrollment and $\operatorname{six}(7 \%, n / N=6 / 86)$ were later diagnosed on follow-up who were initially negative. Seven hypothyroid cases among the autoimmune thyroiditis were treated with thyroxine and became euthyroid on follow-up testing. Compliance to GFD was 52\%. Autoimmune thyroiditis improved on gluten free diet in four cases $(28.6 \%)$. Of the six euthyroid cases at diagnosis three cases became hypothyroid and all were non-compliant.

Conclusion: Frequency of autoimmune thyroiditis was $20 \%$ over a follow-up period of one year. Good compliance with the GFD has some effect on improving autoimmune thyroiditis and maintaining euthyroid status of $C D$ patients.
\end{abstract}

KEYWORDS: Autoimmune thyroiditis, Celiac disease, Gluten-Free Diet.

doi: https://doi.org/10.12669/pjms.36.6.2226

How to cite this:

Rasheed J, Hassan R, Khalid M, Zafar F. Frequency of autoimmune thyroiditis in children with Celiac disease and effect of gluten free diet . Pak J Med Sci. 2020;36(6):1280-1284. doi: https://doi.org/10.12669/pjms.36.6.2226

This is an Open Access article distributed under the terms of the Creative Commons Attribution License (http://creativecommons.org/licenses/by/3.0), which permits unrestricted use, distribution, and reproduction in any medium, provided the original work is properly cited.

1. Dr. Javaria Rasheed, FCPS (Pediatric Medicine). Senior Registrar,

2. Dr. Rushan Hassan,

Post Graduate Trainee, Pediatric Medicine,

3. Dr. Muhammad Khalid, FCPS (Pediatric Medicine), MSc (Epidemiology \& Biostatistics). Senior Registrar,

4. Dr. Fauzia Zafar, FCPS (Pediatric Medicine). Professor \& Head of Pediatrics Department,

1-4: Department of Pediatric Medicine,

Unit-1, Nishtar Hospital Multan, Multan, Pakistan.

Correspondence:

Dr. Javaria Rasheed (FCPS Pediatric Medicine). Department of Pediatric, Medicine Unit-1, Nishtar Hospital Multan, Multan, Pakistan. E-mail: jiyojiya@yahoo.com

* Received for Publication:

* $1^{\text {st }}$ Revision Received:

* $2^{\text {nd }}$ Revision Received:

* Final Revision Accepted:
January 20, 2020

February 26, 2020

June 27, 2020

June 30, 2020

\section{INTRODUCTION}

Celiac disease $(C D)$ is an immune related disease triggered by the intake of wheat gluten and related prolamines from rye and barley in genetically prone individuals. ${ }^{1}$ Recently, global prevalence of $\mathrm{CD}$ is reported to be $1.4 \%$ based on serology and $0.7 \%$ based on biopsy findings. The prevalence of $\mathrm{CD}$ has been reported as $4 \%, 0.5 \%, 0.6 \%$ and $0.8 \%$ in South America, Africa and North America, Asia and Europe and Oceania respectively. ${ }^{2}$

Anti-tissue transglutaminase (tTG) antibody (immunoglobulin IgA) is used as the preferred test to detect $\mathrm{CD}$ in children above two years of age. Jejunal or duodenal biopsy must be done when a child has evident clinical signs but negative 
serological tests after excluding other causes. ${ }^{3}$ The specific therapy for $\mathrm{CD}$ is lifelong avoidance of gluten containing food. ${ }^{4} \mathrm{CD}$ patients are more likely to develop autoimmune diseases such as autoimmune thyroid disorder, Type-I diabetes mellitus (T1DM), pernicious anemia, autoimmune disease of the liver, sarcoidosis, scleroderma and psoriasis. $^{5}$

Autoimmune thyroiditis (AT) is the commonest thyroid disease of the pediatric age group. Genetic susceptibility contributes to approximately $70 \%$ risk of autoimmune thyroiditis in children. It is rare in children below age of one year. ${ }^{6}$ Clinical manifestations of AT vary depending on whether it causes hyperthyroidism or hypothyroidism.? There may be overlap of symptoms of $\mathrm{CD}$ and subtle thyroid dysfunction. Therefore, antibodies to thyroglobulin (TG) and thyroperoxidase (TPO) in blood can be detected years before manifestation of autoimmune thyroid disease. ${ }^{8}$

Management of AT associated with CD depends upon thyroid status and mostly it is management of CD with gluten free diet (GFD) rather than AT. Therefore, therapeutic failures may be result of inappropriate management of $\mathrm{CD}$ or of thyroid disorder, or both. Early detection by screening and appropriate treatment of autoimmune thyroiditis is the building block of successful CD management.

A recent systematic review identified 34 studies on Celiac disease from Pakistan that included 14 studies in pediatric population and five studies on gluten free diet. None of these studies prospectively assessed the effect of gluten free diet on autoimmune thyroiditis. ${ }^{9}$ The objective of the study was to ascertain the frequency of autoimmune thyroiditis in children with $C D$ and to determine the effect of GFD on autoimmune thyroiditis.

\section{METHODS}

After taking permission from Ethical Review Committee (ERC \# 17842-55/NMU), we conducted a prospective observational study at Department of Pediatrics, Nishtar University Hospital Multan from $1^{\text {st }}$ January 2018 to $30^{\text {th }}$ June 2019 . A total of 100 children, ages 1-12 years of either gender diagnosed as $C D$ during study period, were included after informed written consent from parents. Enrollment in the study was completed in June 2018 and last follow-up was completed in June 2019. A sample size of 100 patients was calculated by using $15 \%$ prevalence of anti-thyroid antibodies in Celiac disease patients as reported by Ventura A et al. ${ }^{10}$
With 95\% confidence level and 7\% margin of error.

Diagnosis of Celiac disease was made on the basis of clinical signs and symptoms with laboratory confirmation of serum tTG IgA levels $>10$ times the upper limit of normal, according to European Society for Paediatric Gastroenterology Hepatology and Nutrition (ESPGHAN) criteria for the diagnosis of $\mathrm{CD} .{ }^{11}$ Diagnosis of autoimmune thyroiditis was made on the presence of antithyroperoxidase (anti-TPO $>35 \mathrm{iu} / \mathrm{ml}$ ) or antithyroglobulin (anti-TG $>20 \mathrm{iu} / \mathrm{ml}$ ) antibodies. Patients with $C D$ who were already on GFD and those with congenital hypothyroidism and with thyrotoxicosis secondary to solitary thyroid nodule and multi-nodular goiter were excluded.

Demographic data including patient's age and gender was noted. Laboratory tests for thyroid autoimmunity (anti-TPO and anti-TG) at diagnosis and then at one year after putting patient on GFD were done by manual ELISA technique using Eskulisa kit. Compliance to GFD was assessed by tTG (IgA) levels measured after six months and children with tTG - IgA levels > 10 times normal were considered non-compliant. In AT cases, testing with free $\mathrm{T}_{3} / \mathrm{T}_{4}$ and TSH was done to assess functional thyroid status. The data was entered in and analyzed through SPSS version 23. Age is presented as mean and standard deviation. Median and interquartile range are presented for tTG - IgA levels. Qualitative variables are presented as frequencies and percentages. Chisquare test was used as test of significance for qualitative variables and independent sample t-test for quantitative variables. Mann Whitney U-test was applied for comparison of median.

\section{RESULTS}

During the study period, a total of 100 patients with Celiac disease were enrolled. Mean age of the study participants was $5.94 \pm 3.16$ years and $53 \%$ $(n=53)$ were females. At Celiac disease diagnosis $89 \%(n=89)$ of participants were having height < $5^{\text {th }}$ centile and $94 \%(n=94)$ had weight $<5^{\text {th }}$ centile. Of all the participants $52 \%(n=52)$ were compliant to gluten free diet. Median levels of tTG-IgA antibodies of the participants were $300 \mathrm{IU} / \mathrm{ml}$ at initial diagnosis and $160 \mathrm{IU} / \mathrm{ml}$ at six months after GFD. A total of 20 cases were diagnosed as autoimmune thyroiditis; 14 at the diagnosis of CD and six cases were detected at one year follow up. The mean age of the children with AT was 8.65 \pm 2.4 years compared to $5.2 \pm 2.9$ years in children without AT (Table-I). 
Table-I: Demographic characteristics of children with Celiac Disease $(\mathrm{N}=100)$.

\begin{tabular}{|c|c|c|c|c|}
\hline Characteristic & $\begin{array}{l}\text { Overall } \\
(N=100)\end{array}$ & $\begin{array}{l}\text { Positive anti-thyroid } \\
\text { antibodies }(n=20)\end{array}$ & $\begin{array}{c}\text { Negative anti-thyroid } \\
\text { antibodies }(n=80)\end{array}$ & p-value \\
\hline $\begin{array}{l}\text { Age (years) } \\
(\text { mean } \pm \text { SD) }\end{array}$ & $5.94 \pm 3.16$ & $8.65 \pm 2.45$ & $5.26 \pm 2.95$ & $<0.001^{*}$ \\
\hline \multicolumn{5}{|l|}{ Gender $(n, \%)$} \\
\hline Male & $47(47)$ & $9 \quad(45)$ & $38 \quad(47.5)$ & 0.84 \\
\hline Female & $53(53)$ & $11 \quad(55)$ & $42 \quad(52.5)$ & \\
\hline \multicolumn{5}{|c|}{ Height centiles ( $n, \%)$} \\
\hline$<5^{\text {th }}$ centile & $89(89)$ & $16 \quad(80)$ & $73 \quad(91.25)$ & 0.15 \\
\hline$>5^{\text {th }}$ centile & $11(11)$ & $04 \quad(20)$ & $07 \quad(8.75)$ & \\
\hline \multicolumn{5}{|c|}{ Weight centiles $(n, \%)$} \\
\hline$<5^{\text {th }}$ centile & $94(94)$ & $18 \quad(90)$ & $76 \quad(95)$ & 0.40 \\
\hline$>5^{\text {th }}$ centile & $06(06)$ & $02 \quad(10)$ & $(05)$ & \\
\hline \multicolumn{5}{|c|}{ tTG-IgA levels $\quad$ (median, IQR) } \\
\hline On CD diagnosis & 300,100 & 300,100 & 300,94 & $0.36^{\beta}$ \\
\hline 6-month follow up & 160,180 & 190,231 & 160,173 & $0.95^{\beta}$ \\
\hline \multicolumn{5}{|l|}{ Compliance $(n, \%)$} \\
\hline Compliant & $52(52)$ & $09 \quad(45)$ & $43(53.75)$ & 0.48 \\
\hline Non-compliant & $48(48)$ & $11 \quad(55)$ & $37(46.25)$ & \\
\hline
\end{tabular}

* Independent sample t-test, ${ }^{\beta}$ Mann Whitney U test.

Of 14 patients with $\mathrm{AT}$ at $\mathrm{CD}$ diagnosis, 8 (57.1\%) had anti-TPO positive and $4(28.5 \%)$ were positive for both anti-TPO and anti-TG antibodies. The effects of GFD on thyroid status in 14 children with AT is shown in Table-II. After one year on GFD, five children out of eight with AT remained positive (four compliant with GFD and one noncompliant) and three out of four with AT remain positive for both antibodies. (one compliant who converted from both antibodies +ve to only anti-
TPO +ve and 2 non-compliant). At the end of one year, six new cases from previously negative 86 cases were diagnosed as AT in which anti-TPO were positive $(4$ compliant and 2 non-compliant cases) (Table-II).

Regarding the thyroid functional status; out of initial 14 with AT, six were euthyroid, seven hypothyroid and one was hyperthyroid. All seven hypothyroid and one hyperthyroid patient (on treatment) became euthyroid at the end of

Table-II: Effect of Gluten Free Diet on thyroid antibodies $(\mathrm{n}=20)$ in children with Celiac Disease $(\mathrm{N}=100)$.

\begin{tabular}{lcccc}
\hline & \multicolumn{4}{c}{ 1 year after Gluten free diet } \\
\cline { 2 - 5 } $\begin{array}{l}\text { Anti-thyroid antibodies } \\
\text { At Diagnosis }\end{array}$ & \multicolumn{2}{c}{ Previous cases $(n=14)$} & \multicolumn{2}{c}{ New Cases $(n=6)$} \\
\cline { 2 - 5 } & Compliant & Non-compliant & Compliant & Non-compliant \\
\hline Anti-TPO $^{\beta}(\mathrm{n}=8)$ & 04 & 01 & 04 & 02 \\
Anti- TG $(\mathrm{n}=2)$ & 00 & 02 & 00 & 00 \\
Both TPO and Anti-TG $(\mathrm{n}=4)$ & 01 - only TPO +ve & 02 & 00 & 00 \\
\hline
\end{tabular}

*Anti-TPO - Thyroid-peroxidase antibodies, Anti TG - Anti-thyroglobulin antibodies

$\beta$ Three cases became negative after 1 year of GFD. 
Table-III: Effect of Gluten Free Diet on thyroid function tests $(\mathrm{n}=20)$ in children with Celiac Disease $(\mathrm{N}=100)$.

\begin{tabular}{|c|c|c|c|c|}
\hline \multirow{3}{*}{ Thyroid status on enrollment } & \multicolumn{4}{|c|}{${ }^{*}$ Thyroid status 1 year after Gluten free diet } \\
\hline & \multicolumn{2}{|c|}{ Compliant } & \multicolumn{2}{|c|}{ Non-compliant } \\
\hline & Euthyroid & Hypothyroid & Euthyroid & Hypothyroid \\
\hline Euthyroid $\quad(n=6)$ & $03(50)$ & - & - & $03(50)$ \\
\hline Hypothyroid $(n=7)$ & \multicolumn{4}{|c|}{ All patients received thyroxine and became Euthyroid } \\
\hline Hyperthyroid ( $\mathrm{n}=1)$ & $01(100)$ & - & - & - \\
\hline New cases $\quad(n=6)$ & $02(33.3)$ & - & $03(50)$ & $01(16.7)$ \\
\hline
\end{tabular}

one-year follow-up. At the end of one year, three out of six euthyroid cases became hypothyroid and these were non-compliant. Out of six newly diagnosed AT cases, two were euthyroid and compliant with GFD, and of the four noncompliant cases, three were euthyroid and one was hypothyroid (Table-III).

\section{DISCUSSION}

Our study determined $20 \%$ frequency of autoimmune thyroiditis and documented the $28.6 \%$ improvement in autoimmune thyroiditis over a period of one year follow up on gluten free diet (GFD). Of the twenty AT cases 14 were detected at the diagnosis of CD and 6 on GFD at one year follow up. In a study by Aziz DA et al on 66 children with classic and non-classic CD found that only 2 (3.03\%) had autoimmune thyroiditis..$^{12}$ However, the studies conducted by Meloni A et al and Kalyoncu D et al found higher percentage of AT (10.5\%) among 324 patients with CD and $16.4 \%(11 / 67)$ of children with $\mathrm{CD}$, respectively. ${ }^{13,14}$ The high risk of $\mathrm{CD}$ patients to develop AT is explained by the fact that the Celiac disorder carries one or more MHC or other immune related genes supporting AT.

In our study, children with AT were older compared to those without AT (p-value < 0.001), with no major difference in gender frequency. It may be assumed that the older children who had longer duration of exposure to gluten developed AT compared to those who were younger with lesser duration of exposure. Diamanti A et al. reported that duration of GFD differed notably in Celiac patients with AT in contrast to those without AT (7.9 \pm 0.9 and $10.2 \pm 0.3$ years) but no considerable variation was observed for weight and height achievement (1.8 \pm 1 vs $3.7 \pm 1.5$ and $2 \pm 1$ $\mathrm{kg} /$ year vs $4 \pm 1 \mathrm{~cm} /$ year, respectively). ${ }^{15}$
In our study, eight out of 14 cases with AT $(57.1 \%)$ were anti-TPO +ve at the start of study. At the end of one year, six new cases appeared despite being on GFD and out of those six new cases, four were anti-TPO +ve. This shows that compliance with GFD had no impact on the presence of any particular type of antibody. In a study, Butt $\mathrm{T}$ et al. reported in that anti-TPO antibodies were positive in $16 \%$ patients of CD. ${ }^{16}$ In another study by Hakanen $\mathrm{M}$ et al., the frequency of anti-TPO and anti-TG was $11.4 \%$ and $8.8 \%$ respectively. ${ }^{17} \mathrm{In}$ the present study, presence of anti TPO antibodies had mixed effect on thyroid functional status. Out of initial 14 patients with AT, six were euthyroid, seven hypothyroid and 1 was hyperthyroid. This could be explained by the fact that anti TPO antibody is an early marker of autoimmunity so it appears before the development of functional thyroid dysfunction. The study by Meloni A et al. reported that out of 34 patients, 28 patients were euthyroid and 6 were hypothyroid. ${ }^{13}$ In Italy, Cassio A et al. reported that out of $31 \mathrm{CD}$ patients with AT, $23(74 \%)$ remained euthyroid during the follow up and eight (26\%) had subclinical hypothyroidism. ${ }^{18}$

Though a number of previous studies have shown that duration of gluten intake in Celiac disorder does not relate with the possibility of developing autoimmune illness and that gluten avoidance does not give protection from other auto-immune illnesses, ${ }^{8,18}$ numerous reports proposed that strict compliance with GFD was linked with decreased chances of developing subsequent autoimmune disorders and anti-thyroid antibodies. ${ }^{19,20}$ Guariso et al. have concluded that GFD produces favorable results on the pre-existing clinical auto-immune disorder and may prevent the development of new autoimmune illness. ${ }^{21}$ 
Limitations of the study: Level of thyroid related autoantibodies may reflect the spontaneous fluctuations and transitory normalization in the disease course thus requiring longer duration of follow-up with higher number of patients.

\section{CONCLUSION}

There is increased occurrence of autoimmune thyroiditis in children with Celiac disease. Although good compliance with the GFD has no obvious relationship with the presence or absence of thyroid autoimmunity yet it has clear influence on maintaining euthyroid status of CD patients. Larger, prospective studies with long follow-up are required to explain the clinical importance of anti-thyroid antibodies in children with $C D$ and the influence of GFD on developing autoimmune thyroid disorder.

\section{Grant Support \& Financial Disclosures: None.}

\section{REFERENCES}

1. Branski D, Troncone R. Celiac Disease. In: Kleigman RM, Behrman RE, Stanton BF, editors. Nelson Text Book of Pediatrics. 20th ed. Philadelphia: Elsevier; 2016. p.18351838.

2. Singh P, Arora A, Strand TA, Leffler DA, Catassi C, Green $\mathrm{PH}$, et al. Global prevalence of Celiac disease: Systematic review and meta-analysis. Clin Gastroenterol Hepatol. 2018;16(6):823-836. e2. doi: 10.1016/j.cgh.2017.06.037

3. Rubio-Tapia A, Hill ID, Kelly CP, Calderwood AH, Murray JA. ACG clinical guidelines: Diagnosis and management of Celiac disease. Am J Gastroenterol. 2013;108(5):656-676. doi: 10.1038/ajg.2013.79

4. Valitutti F, Trovato CM, Montuori M, Cucchiara S. Pediatric Celiac disease: follow-up in the spotlight. Adv Nutr. 2017;8(2):356-361. doi: 10.3945/an.116.013292

5. Sharma D, Dubey AP, Singh NK, Khan MH, Maggo S, Keisham R. Celiac disease: confounding presentations of jeopardy in Indians. J Med Sci. 2017;37(6):215-220. doi: 10.4103/jmedsci.jmedsci_15_17

6. Brown RS. Autoimmune thyroiditis in childhood. J Clin Res Pediatr Endocrinol. 2013;5(1):45-49. doi: 10.4274/Jcrpe.855

7. Lerner A, Jeremias P, Matthias T. Gut-thyroid axis and Celiac disease. Endocr Connect. 2017;6(4):52-58. doi: 10.1530/EC-17-0021

8. Hutfless S, Matos P, Talor MV, Caturegli P, Rose NR. Significance of prediagnostic thyroid antibodies in women with autoimmune thyroid disease. J Clin Endocrinol Metab. 2011;96(9):1466-1471. doi: 10.1210/jc.2011-0228

9. Rashid M, Rashid H. Coeliac disease in Pakistan: A bibliographic review of current research status. J Pak Med Assoc. 2019;69(12):1883-1887.

10. Ventura A, Neri E, Ughi C, Leopaldi A, Citta A, Not T. Gluten-dependent diabetes-related and thyroid-related autoantibodies in patients with Celiac disease. J Pediatr. 2000;137(2):263-265. doi: 10.1067/mpd.2000.107160
11. Husby S, Koletzko S, Korponay-Szabo I, Mearin M, Phillips A, Shamir R, et al. European Society for Pediatric Gastroenterology, Hepatology, and Nutrition guidelines for the diagnosis of coeliac disease. J Pediatr Gastroenterol Nutr. 2012;54(1):136-160. doi: 10.1097/ MPG.0b013e31821a23d0

12. Aziz DA, Kahlid M, Memon F, Sadiq K. Spectrum of Celiac disease in Paediatric population: Experience of Tertiary Care Center from Pakistan. Pak J Med Sci. 2017;33(6):13011306. doi: $10.12669 /$ pjms.336.13489

13. Meloni A, Mandas C, Jores RD, Congia M. Prevalence of autoimmune thyroiditis in children with Celiac disease and effect of gluten withdrawal. J Pediatr. 2009;155(1):51-55. doi: 10.1016/j.jpeds.2009.01.013

14. Kalyoncu D, Urganci N. Antithyroid antibodies and thyroid function in pediatric patients with Celiac disease. Int J Endocrinol. 2015; 2015:276575. doi: 10.1155/2015/276575

15. Diamanti A, Ferretti F, Guglielmi R, Panetta F, Colistro F, Cappa M, et al. Thyroid autoimmunity in children with coeliac disease: A prospective survey. Arch Dis Child. 2011;96(11):1038-1041. doi: 10.1136/ archdischild-2011-300595

16. Butt T, Mumtaz A, Qasim A, Hameed N, Azhar K, Ibrahim M. Assessment of Thyroid Dysfunction in children with Celiac Disease. Biomedica. 2011;27(2):123-127.

17. Hakanen M, Luotola K, Salmi J, Laippala P, Kaukinen K, Collin P. Clinical and subclinical autoimmune thyroid disease in adult Celiac disease. Dig Dis Sci. 2001;46(12):26312635. doi: 10.1023/a:1012754824553

18. Cassio A, Ricci G, Baronio F, Miniaci A, Bal M, Bigucci B, et al. Long-term clinical significance of thyroid autoimmunity in children with Celiac disease. J Pediatr. 2010;156(2):292295. doi: 10.1016/j.jpeds.2009.08.047

19. Cosnes J, Cellier C, Viola S, Colombel JF, Michaud L, Sarles J, et al. Incidence of autoimmune diseases in Celiac disease: Protective effect of the gluten-free diet. Clin Gastroenterol Hepatol. 2008;6(7):753-758. doi: 10.1016/j. cgh.2007.12.022

20. Krysiak R, Szkrobka W, Okopien B. The effect of glutenfree diet on thyroid autoimmunity in drug-aaïve women with Hashimoto's Thyroiditis: A pilot study. Exp Clin Endocrinol Diabetes. 2019;127(07):417-422. doi: 10.1055/a0653-7108

21. Guariso G, Conte S, Presotto F, Basso D, Brotto F, Pozza LVD, et al. Clinical, subclinical and potential autoimmune diseases in an Italian population of children with coeliac disease. Aliment Pharmacol Ther. 2007;26(10):1409-1417. doi: 10.1111/j.1365-2036.2007. 03526.x

\section{Author`s Contribution:}

JR: Conception of idea, Manuscript writing, Data collection. Also, responsible and accountable for the accuracy / integrity of the work

RH: Data collection, Literature review.

MK: Data analysis, Statistical analysis, Critical analysis of manuscript.

FZ: Final approval and guarantor of the study. 